\title{
Alcohol impairs visual presence/absence detection more for females than for males
}

\author{
LLOYD L. AVANT \\ Iowa State University, Ames, Iowa
}

\begin{abstract}
Ninety subjects ( 45 males, 45 females) were given $0.0,0.5$, or $1.0 \mathrm{ml} / \mathrm{kg}$ body weight of 190 . proof ethanol and tested for chance-level presence/absence detection thresholds with energy-masked presentations of traffic signs and blank inputs. Alcohol produced higher blood alcohol concentration (BAC) levels, and higher detection threshold durations, for females than for males. These results indicate that alcohol influences precortical visual processing and that the influence is greater for females than for males. The higher bioavailability of alcohol in women is likely due to less gastric oxidation of ethanol in women than in men.
\end{abstract}

Hills (1980) estimated that over $90 \%$ of the information input to the driver of an automobile is visual. The importance of understanding the effects of alcohol on vision should not be underestimated; however, the literature presents conflicting claims about the influence of alcohol on vision. Between 1940 and 1984, at least eight literature reviews indicated that perception was minimally affected by alcohol (Carpenter, 1961; Grant, 1970; Jellinek \& McFarland, 1940; Jones \& Joscelyn, 1978; Marshall, 1941; Moskowitz, 1974; Voas, 1984; Wallgren \& Barry, 1970). In their discussion of the neuropsychology of alcoholism, Tarter and Edwards (1985, p. 220) concluded that "the investigations conducted to date do not reveal a disturbance in basic perceptual processes." Similar conclusions have been offered in discussions of alcohol and central nervous system function (e.g., Mitchell, 1985), pharmacology (e.g., Pohorecky \& Brick, 1988; Ritchie, 1985), neuropathology (e.g., Freund, 1985), and brain biochemistry (e.g., Hoffman \& Tabakoff, 1985).

These reviews leave little reason to expect peripheral (precortical) visual processing to be impaired by moderate doses of alcohol. Other studies suggest, however, that it may be premature to consider even retinal processes immune to the effects of alcohol. For example, alcohol has been reported to influence the action of certain neurotransmitters (e.g., Carmichael \& Isreal, 1975; Kalant \& Grose, 1967), the b-wave and c-wave of the electroretinogram (e.g., Ikeda, 1963; Skoog, 1974), retinal and optic nerve transmission of color information (e.g., Grutzner, 1972; Mergler, Blain, Lemaire, \& Lalande,

This research was supported by a grant from the Alcoholic Beverage Medical Research Foundation. The paper was written while the author was a visiting scientist at the MRC Applied Psychology Unit, Cambridge, England. I thank Mark Bowes, Michael Tepin, and Kathryn Kerwin for assistance in collecting data, Arnold Wilkins, F. W. Campbell, and Hisako Ikeda for helpful discussions of the data, Ian Nimmo-Smith and Robert Strahan for discussion of the statistical evaluation of the data, and Veronica Dark, Michael O'Boyle, Alice Thieman, and Tom Turnage for their critical readings of the manuscript. Correspondence should be addressed to Lloyd L. Avant, Department of Psychology, Iowa State University, Ames, IA 50011.
1988), and recovery from the effects of glare and contrast sensitivity (e.g., Adams, 1978; Adams, Brown, \& Flom, 1976).

The visual masking procedure has not been used to examine the effects of alcohol on vision. Turvey (1973) has shown, however, that the procedure can distinguish between peripheral (precortical) and central (cortical) processing. To obtain masking in the peripheral visual system, the mask must be of greater energy than the target item, and the mask and target must be presented to the same eye. Such masking can function in both a forward and a backward direction. Central pattern masking can be obtained whether the target and mask inputs are to the same or to different eyes. It is governed by stimulus onset asynchrony between target and mask rather than by the energy relationship between the two. It functions primarily in a backward manner, and it requires some pattern similarity between target and mask stimuli.

Avant et al. (1988) used a pattern-masking procedure to investigate central processing of traffic signs. The study showed that, although the average pre- and postmasked exposure duration for chance-level presence/absence detection of traffic signs was $24 \mathrm{msec}$, the action message of the signs (Stop, move Left, move Right, Slow Down) gained central processing when input durations were as brief as $4 \mathrm{msec}$. The present experiment used an energymasking procedure, with the intent of limiting processing to the peripheral visual system, to determine whether moderate doses of alcohol could influence peripheral processing of the traffic signs employed by Avant et al. (1988). The rationale for the experiment assumed that energy masking does limit processing to precortical stages and tested two hypotheses. First, if alcohol does not influence peripheral processing, then moderate doses of alcohol should not influence the minimum exposure duration required for chance-level presence/absence sign detection. Second, if alcohol influences peripheral processing, then the masking procedure should not permit sign messages to affect performance accuracy, because, to have such an effect, sign messages would require cortical processing. 


\section{METHOD}

\section{Subjects}

Ninety undergraduate students (45 males, 45 females) were recruited by ads in the campus newspaper. Telephone responses to the ads permitted the experimenters to interview each subject, using a health history questionnaire to ensure that volunteers had no health problems with which alcohol could interfere. Volunteers were excluded if they had been intoxicated within the preceding week, and the subjects were instructed to abstain from alcohol for $24 \mathrm{~h}$, and from food for $4 \mathrm{~h}$, before their appointments in the laboratory. When the subjects arrived at the laboratory, they filled out and signed the same health history questionnaire as well as an informed-consent statement.

Drinking histories averaged one drink per week for both males and females. Males weighed significantly more $($ mean $=189 \mathrm{lb})$ than females (mean $=144 \mathrm{lb} ; F(1,84)=46.42, p<.001$ ). For neither males nor females did weights differ among the $0.0-, 0.5-$, and $1.0-\mathrm{ml} / \mathrm{kg}$ alcohol dose levels. The subjects' ages ranged from 21 to 35 , averaged 22.24 years, and did not differ between sexes or among alcohol dose levels. The subjects were required to have normal or corrected-to-normal vision and to speak English as their native language.

Fifteen males and 15 females were tested under one of three dose levels: $0.0,0.5$, or $1.0 \mathrm{ml} / \mathrm{kg}$ body weight of 190 -proof ethanol blended 1:5 with lemonade crystals mixed with water at 1.5 times the lemonade manufacturer's recommendation. Administration of the alcohol was by a double-blind procedure. The principal investigator (PI) mixed all drinks, and three assistants, who were unaware of each subject's dose level, collected threshold data. The subjects neither saw their drinks mixed nor were told the alcohol dose level to which they were assigned. Each subject was paid $\$ 10$ for participating in the research.

\section{Stimulus Materials}

The sample of traffic signs, shown in Figure 1, included 15 regulation signs and one nonregulation diamond-shaped red Stop sign. The sample included four signs which required each of four driver action decisions: Stop, move Left, move Right, and Slow Down. For each driver action, two variants of the message were used: Stop action messages were Stop and Do Not Enter, move Left (Right) messages were Keep Left (Right) and Merge Left (Right), and Slow Down messages were Stop Ahead and Signals Ahead. Where possible, a word-only and a symbol-only sign presenting each message were selected; where this was not possible, the sign was identified as either a word or symbol sign by the predominant property of the sign. The signs were photographed for presentation as $2 \times$ 2 in. color slides in a Scientific Prototype tachistoscope.

\section{Procedure and Design}

The mask field of the tachistoscope was adjusted to project $138.6 \mathrm{~cd} / \mathrm{m}^{2}$; the stimulus field was adjusted to project $38.8 \mathrm{~cd} / \mathrm{m}^{2}$. These luminance levels were determined empirically to permit threshold exposure durations in the range of 1 to $60 \mathrm{msec}$ in pilot testing before the main experiment. For each trial, the mask field also provided the adaptation field, and stimulus inputs were essentially interruptions in the subject's viewing of that field. A "ready" signal from the experimenter at the beginning of each trial cued the subject to fixate the center of the mask field. Trials were separated by about $10 \mathrm{sec}$, the time required for the experimenter to record the subject's response, to remove the current test slide from the tachistoscope, and to insert the slide for the next test trial.

Upon arrival at the laboratory, each subject was weighed by the PI, who then mixed a drink appropriate to the subject's alcohol dose assignment. The drink was served, with two ice cubes, in a lidded plastic cup with an inserted straw. The subjects were not rushed, but were asked to consume the drink in about 20-30 min. After finishing the drink, each subject was asked to wash out his/her mouth
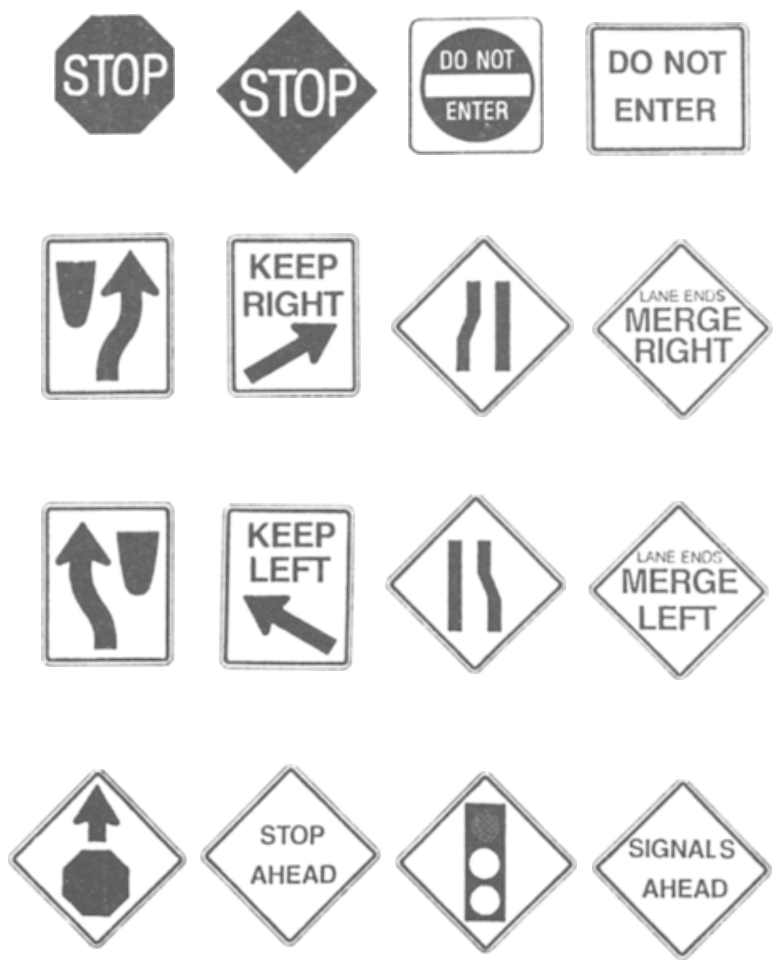

Figure 1. Illustrations of the signs used in the present research.

several times at a water fountain before blood alcohol concentration (BAC) was tested with a CMI Model 4011AS intoxilizer, which estimates BAC using infrared spectroscopy of a breath sample. The subject was then escorted to the lab to begin data collection. The time required to determine a threshold duration varied across subjects from approximately 30 to $75 \mathrm{~min}$. Each subject was then returned to the PI, who tested BAC again. Each subject was then tested at 30 -min intervals until $B A C$ was below .05 , at which time the PI transported the subject home.

In the threshold-setting procedure, the first series of 16-sign and 16-blank, randomly ordered, test inputs was presented for $70 \mathrm{msec}$, and the difference between blank and sign presentations was clearly visible to the subject. To ensure a rigorous detection threshold exposure duration, exposure durations were reduced over succeeding series of trials until the subject reached chance level in reporting whether test inputs contained a sign or were blank; that is, the subject made no more than 16 correct sign/blank decisions out of the 32 test inputs of the series. For each subject, an exposure duration was determined that produced, at best, chance-level detection over three successive series of trials (i.e., no more than 48 correct responses on 96 trials). When that criterion was met, assuring that the subject was just guessing on each trial, three additional series were presented at that duration. The number of correct responses was recorded for each of the three criterion series and the three following series of trials at the threshold exposure duration, providing 192 test trials at the threshold duration. Subjects whose use of either the "present" or "absent" response exceeded a 95\% confidence interval around a proportion of .5 were excluded.

The measures submitted to statistical evaluation were (1) BAC levels before and after threshold determination, (2) exposure duration at which chance-level performance was reached, and to test the effect of sign message on presence/absence detection, (3) $d^{\prime}$, 
for the four sign messages at the threshold exposure duration. For the analysis of BAC levels, dose level and sex were between-subjects factors, and time of test (before vs. after threshold determination) was the within-subjects factor. For the evaluation of threshold exposure durations, dose level and sex were between-subjects factors. For the evaluation of $d^{\prime}$, dose level and sex were betweensubjects factors and sign message was the within-subjects factor.

\section{RESULTS}

\section{BAC Levels}

The BAC for the placebo condition was, of course, zero. The .5- and $1.0-\mathrm{ml}$ dose levels produced a significant difference in BAC levels [means $=.035$ and .072 , respectively; $F(1,56)=110.11, p<.001]$. Overall, BAC was higher for females (mean $=.057$ ) than for males [mean $=.049 ; F(1,56)=5.19, p<.05]$. Although the interaction between sex and time of BAC test (before vs. after threshold determination) was not significant $[F(1,56)=1.51, p>.05]$, simple main effect tests between males and females within that interaction showed the mean BAC for females (.060) to be higher than that for males (.049) before threshold determination $[F(1,56)=$ $7.69, p<.01$ ], but not after the determination [mean BACs $=.055$ and .050 , respectively; $F(1,56)=1.29$, $p>.05]$.

The interaction between dose level and time of BAC test was significant $[F(1,56)=18.25, p<.001]$. Mean BACs for each dose level before and after threshold determination for both males and females are presented in Table 1. For the .5-ml dose, BAC level decreased from before to after threshold determination; for the $1.0-\mathrm{ml}$ dose, BAC level increased from the initial BAC test to the test after the threshold-setting task.

\section{Threshold Exposure Duration}

Two simple analyses evaluated threshold exposure durations. The first addressed only the placebo condition to determine whether, without alcohol, males and females differed in threshold exposure durations; the analysis showed the threshold exposure duration for males $(14.3 \mathrm{msec})$ to be nonsignificantly lower than that for females ( $16.5 \mathrm{msec})$. The second analysis tested effects of sex and the .5- and 1.0-ml $/ \mathrm{kg}$ dose levels. The main effect of dose level was not significant, but the main effect of sex was significant $[F(1,56)=4.424, p<.05]$; there was no interaction between dose level and sex. Mean

\section{Table 1}

Mean Blood Alcohol Concentration (BAC) Before and After Threshold Determination for Each Alcohol Dose Level for Males and Females

\begin{tabular}{|c|c|c|c|c|c|}
\hline & \multicolumn{4}{|c|}{ Dose Level } & \multirow[b]{3}{*}{$M$} \\
\hline & \multicolumn{2}{|c|}{0.5} & \multicolumn{2}{|c|}{1.0} & \\
\hline & Before & After & Before & After & \\
\hline Males & .038 & .027 & .059 & .073 & .049 \\
\hline Females & .045 & .029 & .074 & .080 & .057 \\
\hline Mean & .042 & .028 & .067 & .077 & \\
\hline
\end{tabular}

Note-Dose level in $\mathrm{ml} / \mathrm{kg}$ body weight of 190 -proof ethanol.
Table 2

Mean Threshold Exposure Duration (in milliseconds) for Males and Females at Each Dose Level

\begin{tabular}{lcccc}
\multicolumn{5}{c}{ Males and Females at Each Dose Level } \\
\cline { 2 - 5 } & \multicolumn{3}{c}{ Dose Level } & \multicolumn{1}{c}{$\boldsymbol{M}$} \\
\cline { 2 - 5 } & 0.0 & 0.5 & 1.0 & 15.76 \\
Males & 14.27 & 15.33 & 17.67 & 15.29 \\
Females & 16.00 & 20.67 & 24.20 & 20.29 \\
Mean & 15.14 & 18.00 & 20.94 & \\
\hline
\end{tabular}

Note-Dose level in $\mathrm{ml} / \mathrm{kg}$ body weight of 190 -proof ethanol.

threshold durations for males and females at each dose level are presented in Table 2. Mean threshold for males under alcohol dosage $(16.5 \mathrm{msec})$ was significantly lower than that for females at comparable dosage $(22.4 \mathrm{msec})$. Thus, while variance among subjects was too large to reveal a significant dose level $\times$ sex interaction, the effect of alcohol on chance-level detection thresholds was 2.99 times larger for females (placebo:alcohol difference = $6.4 \mathrm{msec}$ ) than for males (placebo:alcohol difference $=$ $2.2 \mathrm{msec}$ ).

Given that energy masking interferes with precortical processing (Turvey, 1973), the effect of alcohol on detection thresholds indicates that moderate doses of alcohol do influence peripheral processing and that the effect of alcohol is greater for females than for males. These results join other data in showing that comparable doses of alcohol (by total body weight) produce higher BAC levels in females than in males (e.g., Marshall, Kingstone, Boss, \& Morgan, 1983; Williams, MacLean, \& Cairns, 1983). The particular merit of the present results is that they show that the effect of alcohol extends to retinal processes that directly influence behavioral responses to important stimulus inputs.

If it is reasonable to assume that the present/absent response execution requirements are the same under energy masking and pattern masking, such that threshold exposure duration reflects how far into the eye-brain system the mask permits input information to be processed and/or how rapidly the result or record of automatic and unconscious operations on the input can be brought into awareness, then one might expect a briefer threshold exposure duration for energy masking than for pattern masking. The present results and those from Avant et al. (1988) conform to this expectation; for the energy masking of the present experiment, mean threshold duration was $18 \mathrm{msec}$, and for the pattern masking of the previous study, mean threshold exposure duration was $24 \mathrm{msec}$.

\section{Signal Detection $d^{\prime}$}

As reported above, threshold exposure durations were lengthened, especially for females, by alcohol. An alternative method of indexing effects of alcohol on the ability to detect stimulus inputs is to compute $d^{\prime}$ for each of the four sign messages at each subject's presence/absence threshold. The $d^{\prime}$ measure offers a means of testing the possibility that the energy masking of the present experiment limited processing of the signs to the peripheral visual system before sign messages could gain cortical 
processing, whereas the pattern masking of the Avant et al. (1988) study permitted cortical processing of sign messages. To compute $d^{\prime}$ s for the two sets of data, we computed false-alarm rates for the entire stimulus set, since no incorrect "present" response could identify any sign for which the response was a false alarm. Then we computed hit rates and $d$ 's for the Stop, Slow, Left, and Right message signs. For the present data, those mean $d$ 's were, respectively, $-.234,-.309,-.260$, and -.307 . These negative $d^{\prime}$ 's show that false alarms outnumbered hits; analysis of the $d$ 's showed no significant difference among the four sign messages. In the Avant et al. (1988) study, stimulus and mask fields were equated for luminance $\left(58.21 \mathrm{~cd} / \mathrm{m}^{2}\right)$ before the experiment began, and stimulus inputs were pre- and postmasked by a pattern mask presenting a montage of small pieces of the 16 signs. In that study, both mean hit rate and mean false-alarm rate $=.48$ computed across the entire stimulus set; thus $d^{\prime}$ for the entire stimulus set was zero. However, when $d^{\prime}$ was computed for each sign message, as in the present experiment, mean $d^{\prime}$ 's for Stop, Slow, Left, and Right messages were $.119,-.102,-.057$, and -.044 , respectively. Analysis of variance showed these means to differ $[F(3,87)=3.90, p<.02]$; the NewmanKeuls test $(\alpha=.05)$ showed that $d^{\prime}$ for the Stop message was larger than those for the other three messages, which did not differ. The comparison of these two studies makes the important point that the energy masking of the present experiment did not permit cortical processing of the sign messages that did gain cortical analysis with the pattern masking of the Avant et al. (1988) study.

\section{DISCUSSION}

Given that the present data reflect peripheral visual processing, the data suggest two conclusions: First, peripheral visual processing is affected by moderate doses of alcohol, and second, alcohol affects peripheral processing more for females than for males. Both of these conclusions should be drawn with caution and not without evidence from other experimental procedures that converge with the present evidence from the energy-masking procedure.

Two types of evidence are particularly pertinent to the present results: One type shows the effect of alcohol on the ERG (e.g., Bernhard \& Skoglund, 1941; Ikeda, 1963; Ikeda \& Granger, 1963; Jacobson, Hirose, \& Stokes, 1969; Wallgren \& Barry, 1970). The other type identifies the likeliest cause of the greater effect of alcohol on females than on males (Frezza et al., 1990).

\section{Alcohol and the ERG}

Wallgren and Barry (1970) state that "Effects of alcohol or other drugs can generally be attributed to alterations of the afferent input from the sense organs [italics added] or changes of the CNS response"' (p. 287). For example, Jacobson, Hirose, and Stokes (1969) reported that the a-wave of the electroretinogram (ERG) was in- creased by alcohol when the dark-adapted eye was tested with red light ( $>610 \mathrm{~nm}$ : Kodak Wratten filter No. 92) or with intense white light. Ikeda (1963) states that the a-wave originates in the outer segments of the photoreceptors, whereas the $b$-wave originates in the neural layer (bipolar potential) of the retina. Ikeda (1963) reported that a 0.75 -g/kg-of-body-weight dose of alcohol increased the ERG b-wave evoked by a single flash under complete dark adaptation. Both rise time and recovery of the b-wave were slowed by alcohol. In Ikeda's (1963) data, the amplitude of the b-wave reached an asymptote (at about $580 \mu \mathrm{V}$ ) within $90 \mathrm{~min}$ in darkness; administration of alcohol at that time increased b-wave amplitude by nearly $100 \mu \mathrm{V}$. These results led Ikeda $(1963$, p. 165$)$ to conclude that "the effects of alcohol on the ERG are basically similar to those produced by increased darkadaptation." The selective effect of alcohol on the P II component of the ERG of the frog eye also suggested to Bernhard and Skoglund (1941) that alcohol produces a change in neural organization similar to that which occurs with dark adaptation (see also Ikeda \& Granger, 1963; Wallgren \& Barry, 1970). This change in neural organization appears to be an increase in a summative mechanism of the neurons at the bipolar cells. Skoog (1974) reported that the c-wave is also altered by alcohol.

Ikeda (1963) noted that, under normal physiological conditions, alcohol is absorbed into the bloodstream and enters the retina through the central retinal artery from the ophthalmic artery. The blood supply from the central retinal artery encroaches on the inner nuclear layer, but no capillaries reach the rods and cones, which are entirely supplied by the choroid into which the posterial ciliary arteries ramify. Effects of alcohol occur rapidly, because the maximum effect of alcohol ingestion on the ERG occurs in a shorter time after ingestion (20-30 min) than does the maximum concentration of alcohol in the blood (45-60 min).

Testing BAC levels in the range from $.04 \%$ to $.06 \%$, Levett and Jaeger (1980) reported that an oscillatory b'wave following the ERG $b$-wave can be abolished by alcohol, and that it returns to normal with 1-2 days of alcohol abstinence. Levett and Jaeger hypothesize that the $b^{\prime}$ 'wave, as well as the $b$-wave, are mediated by potassium $\left(\mathrm{K}^{+}\right)$shifts in the retina.

\section{Alcohol and Sex of Subject}

The present results are not the first to show different effects of alcohol on males and females. Some researchers consider the method of determining alcohol dosage to be critical in studies of alcohol effects on males and females. When dosage is based on total body weight, there appears to be considerable variability in pharmacokinetics. For example, Dubowski $(1976,1985)$ reported that elapsed time from end of alcohol intake to peak BAC varied from 14 to $138 \mathrm{~min}$, and mean times for men and women were 57 and $42 \mathrm{~min}$, respectively. These data suggest that, on average, the time to peak BAC after the end of drinking is 1.35 times as long for men as for women. Also, the 
mean peak BAC:dose relationship was found to be $12.8 \%$ higher in women than in men. In sleep research on young women, Williams, MacLean, and Cairns (1983) found that BACs were 1.7 times higher than those for men at comparable doses.

There are, however, indications that it is more appropriate to base dosage on total body water weight than on total body weight. Alcohol is infinitely soluble in water, so that at equilibrium in blood circulation it is distributed equally throughout the body water. If dosage is by total body water weight, many of the sex differences seen with dosage by total body weight disappear, because percent water weight is generally found to be higher in females. For example, Marshall et al. (1983) found that, in subjects dosed by total body weight, both mean peak blood ethanol values and mean area under the concentrationtime curve (AUC) were higher for women than for men; however, if values were adjusted for sex differences in total body water weight, mean AUC and volume of alcohol distribution no longer differed between the sexes. Similar findings have been reported by Cocco, Adler, Westrick, Nathan, and Brick (1986) and by Goist and Sutker (1985), although calculations for total body water weight vary, depending, in part, on methodology. For example, Pohorecky and Brick (1988) suggest values of 58\% and $48 \%$ of total body weight for males and females, respectively (Cocco et al., 1986; Watson, Watson, \& Butt, 1981). Marshall et al. (1983) reported 65\% and 51\% of total body weight as total body water weight for their males and females, respectively.

More recent evidence indicates that the important difference in alcohol effects on the two sexes depends less on whether dosage is by total body weight or total body water weight than on whether dosage is oral or intravenous. Frezza et al. (1990) reported a study of "first-pass metabolism" of alcohol in the stomach as opposed to intravenous intake of alcohol. These researchers dosed male and female subjects orally or intravenously and tracked $\mathrm{BAC}$ for $5 \mathrm{~h}$. The telling measure was the area under the curve of blood alcohol concentrations after oral and intravenous administration of alcohol at $.3 \mathrm{~g} / \mathrm{kg}$ of body weight. Frezza et al. (1990) report that "women had higher blood ethanol concentrations than males after orally ingesting an equivalent dose of alcohol. By contrast, no sex-related differences were found when ethanol was administered intravenously"' (p. 96). The first-pass metabolism and gastric dehydrogenase activity of the women were, respectively, $23 \%$ and $59 \%$ of those in the men, and there was a significant correlation $\left(r_{s}=.659\right)$ between first-pass metabolism and gastric mucosal alcohol dehydrogenase activity. This lack of gastric oxidation of ethanol in women increases bioavailability of ethanol in the vascular system, facilitating the delivery of ethanol to retinal tissue.

\section{Conclusion}

Having found that alcohol produced a decline in the bwave amplitude of 5 cycles/sec flicker ERG, Ikeda (1963) pointed out that "the retina influenced by alcohol is highly sensitive to light, but so slow in response that it is incapable of following a rapidly repetitive stimulus"' (p. 165). According to Ikeda, this indicates that the eye is roddominated after alcohol. Consideration of Frezza et al.'s (1990) evidence that a lack of gastric oxidation of alcohol produces greater bioavailability of ethanol in women and Ikeda's (1963) evidence that alcohol appears to increase a summative mechanism at the bipolar cell level which functions, like dark adaptation, to diminish the ability to discriminate between bright lights may provide an account of the sex difference in threshold exposure durations observed in the present experiment. The higher BACs for females may have resulted in a greater role for rod vision in females than in males, such that the difference between the target field $\left(38.8 \mathrm{~cd} / \mathrm{m}^{2}\right)$ and the mask field $\left(138.6 \mathrm{~cd} / \mathrm{m}^{2}\right)$ would require longer exposures of the target field for females to achieve a minimum discrimination of a blank versus a filled field.

\section{REFERENCES}

Adams, A. J. (1978). Acute effects of alcohol and marijuana on vision. In S. J. Cool \& E. L. Smith III (Eds.), Frontiers in visual science (pp. 93-105). New York: Springer-Verlag.

Adams, A. J., Brown, B., \& Flom, M. C. (1976). Alcohol-induced changes in contrast sensitivity following high-intensity light exposure. Perception \& Psychophysics, 19, 219-225.

Avant, L. L., Nelson, J. N., Short, N., Connerley, M., Bowes, M., Thieman, A. A. (1988). Prerecognition sensory and cognitive processing of traffic signs. In A. G. Gale, M. H. Freeman, C. M. Haslegrave, P. Smith, \& S. P. Taylor (Eds.), Vision in vehicles-II (pp. 289-298). New York: North-Holland.

Bernhard, C. G., Skoglund, C. R. (1941). Selective suppression with ethyl alcohol of inhibition in the optic nerve and of the negative component P III of the electroretinogram. Acta Physiologica Scandinavica, 2, 10-21

Carmichael, F. J., \& Israel, Y. (1975). Effects of ethanol on neurotransmitter release by rat brain cortical slices. Journal of Pharmacology \& Experimental Therapeutics, 193, 824.

CARPENTER, J. A. (1961). Effects of alcohol on some psychological processes: A critical review with special reference to automobile driving skill. Quarterly Journal of Studies on Alcohol, 23, 274-314.

Cocco, K., Adler, J., Westrick, E., Nathan, P., \& Brick, J. (1986) Computerized program for the calculation of target blood alcohol levels in humans. Proceedings and Abstracts of the Annual Meeting of the Eastern Psychological Association, 57, 29.

DUBOWSKI, K. M. (1976). Human pharmacokinetics of ethanol: I. Peak blood alcohol concentrations and elimination in male and female subjects. Alcohol Technical Reports, 5, 55-63.

DUBowskı, K. M. (1985). Absorption, distribution, and elimination of alcohol: Highway safety aspects. Journal of Studies on Alcohol, Supplement 10, 98-108.

FreUND, G. (1985). Neuropathology of alcohol abuse. In R. E. Tarter \& D. H. Van Thiel (Eds.), Alcohol and the brain: Chronic effects (pp. 3-16). New York: Plenum Medical.

Frezza, M., di Padova, C., Pozzato, G., Terpin, M., Baraona, E., \& Lieber, C. (1990). High blood alcohol levels in women. New England Journal of Medicine, 322, 95-99.

GoIST, K., \& SuTKer, P. (1985). Acute alcohol intoxication and body composition in women and men. Pharmacology, Biochemistry, \& Behavior, 22, 811-814.

Grant, W. M. (1970). Drug-induced disturbances in vision that may affect driving. In A. H. Keeney (Ed.), Proceedings of the Eleventh Annual Meeting of the American Association of Automotive Medicine (pp. 192-200). Springfield, IL: Thomas. 
GrutzNeR, P. (1972). Acquired color vision defects. In D. Jameson \& L. M. Hurvich (Eds.), Handbook of sensory physiology VII/4 (pp. 643-659). New York: Springer-Verlag.

HıLss, B. L. (1980). Vision, visibility, and perception in driving. Perception, 9, 183-216.

Hoffman, R. L., \& TABAKoFf, B. (1985). Ethanol's action on biochemistry. In R. E. Tarter \& D. H. Van Thiel (Eds.), Alcohol and the brain: Chronic effects (pp. 19-68). New York: Plenum Medical.

IKEDA, H. (1963). Effects of ethyl alcohol on the evoked potential of the human eye. Vision Research, 3, 155-169.

IKEDA, H. , \& GRANGER, G. W. (1963). Action of alcohol on visual and retinal responses to intermittent illumination. In Alcohol and road traffic (pp. 140-146). Proceedings of the 3rd International Conference, London: British Medical Association.

Jacobson, J. H., Hirose, T., \& Stokes, P. E. (1969). Changes in human ERG induced by intravenous alcohol. Ophthalmologia Additamentum, 157, 669-677.

Jellinek, E. M., \& McFarland, R. A. (1940). Analysis of psychological experiments on the effects of alcohol. Quarterly Journal of Studies on Alcohol, 1, 272-371.

JONES, R. K., \& JOSCELYN, K. B. (1978). Alcohol and highway safety 1978: A review of the state of knowledge (Contract No. DOT HS-501217, Final Report). Washington, DC: U.S. Department of Transportation, National Highway Traffic Safety Administration.

KALANT, M., \& GROSE, W. (1967). Effects of ethanol and pentobarbitol on release of acetylcholene from cerebral cortical slices. Joumal of Pharmacology \& Experimental Therapeutics, 158, 386-393.

LEVETT, J., \& JAEGER, R. (1980). Effects of alcohol on retinal potentials, eye movements, accommodation, and the pupillary light reflex. In W. H. Merigan \& H. Weiss (Eds.), Neurotoxicity of the visual system (pp. 87-100). New York: Raven Press.

Marshall, A. W., Kingstone, D., Boss, M., \& Morgan, M. Y (1983). Ethanol elimination in males and females: Relationship to menstrual cycle and body composition. Hepatology, 3, 701-706.

Marshall, H. (1941). Alcohol: A critical review of the literature 19291940. Psychological Bulletin, 38, 193-217.

Mergler, D., Blain, L., Lemaire, J., \& Lalande, F. (1988). Colour vision impairment and alcohol consumption. Neurotoxicology \& Teratology, 10, 255-260.
MitCheLl, M. C. (1985). Alcohol-induced impairment of central nervous system function: Behavioral skills involved in driving. Journal of Studies on Alcohol, Supplement 10, 109-116.

Moskowitz, H. (1974). Alcohol influences upon sensory motor function, visual perception, and attention. In Alcohol, drugs, and driving (Contract No. DOT-HS-265-2-489, Final Report, pp. 49-69; NTIS Document PB 232 111). Washington, DC: U.S. Department of Transportation, National Highway Traffic Safety Administration.

PoHORECKY, L. A., \& BrICK, J. (1988). Pharmacology of ethanol. Pharmacology \& Therapeutics, 36, 335-427.

Ritchie, J. M. (1985). The aliphatic alcohols. In A. C. Gilman, L. S. Goodman, T. W. Roll, \& F. Murad (Eds.), Gordon and Gilman's The pharmaceutical basis of therapeutics, 7, 372-386.

SKOoG, K. (1974). The c-wave of the human D. C. registered ERG: III. Effects of ethyl alcohol on the c-wave. Acta Ophthalmologica, 52, 913-923.

TARTER, R. E., \& EDWARDS, K. L. (1985). Neuropsychology of alcoholism. In R. E. Tarter \& D. H. Van Theil (Eds.), Alcohol and the brain: Chronic effects (pp. 217-242). New York: Plenum Medical.

TURVEY, M. T. (1973). On peripheral and central processes in vision: Inferences drawn from an information processing analysis of masking with patterned stimuli. Psychological Review, 80, 1-52.

VoAs, R. B. (1984). Alcohol and highway safety 1984: A review of the state of knowledge (Contract No. DOT-HS-806-569). Washington, DC: U.S. Department of Transportation, National Highway Traffic Safety Administration.

WallgRen, H., \& BaRRY, H., IU (1970). Actions of alcohol: Vol. 1. Biochemical, physiological, and psychological aspects. New York: Elsevier.

Watson, P. E., Watson, I. D., \& Butt, R. D. (1981). Prediction of blood alcohol concentrations in human subjects: Updating the Widmark equation. Journal of Studies on Alcohol, 42, 547-556.

Williams, D. L., Maclean, A. W., \& Cairns, J. (1983). Doseresponse effects of ethanol on the sleep of young women. Journal of Studies on Alcohol, 44, 512-523.

(Manuscript received October 2, 1989; revision accepted for publication April 17, 1990.)

\title{
Notices and Announcements
}

\author{
31st Annual Meeting of the Psychonomic Society \\ New Orleans, Louisiana \\ November 16-18, 1990
}

The 31st Annual Meeting of the Psychonomic Society will be held in New Orleans, November 16-18, 1990. The meetings will begin Friday morning and continue until Sunday at noon. The headquarters hotel will be the Hyatt Regency.

The program and hotel reservation cards will be mailed to members and associates in September. A copy of the program will be published in the November issue of the Bulletin of the Psychonomic Society.

For further information, please contact the secretary-treasurer of the Society: Cynthia H. Null, Psychology Department, College of William \& Mary, Williamsburg, Virginia 23185 (Telephone: 804-221-3882; BITNET: WPSLCHN@WMMVS). 